\title{
INVESTIGACIÓN/RESEARCH
}

\section{LAS FUNCIONES DE LOS MEDIOS DE COMUNICACIÓN EN LA VIDA DE UNA PERSONA MAYOR}

Mencía de Garcillán López- Rúa. Universidad Complutense de Madrid. España. menciag@yahoo.com

Gema Martínez Navarro. Universidad Complutense de Madrid. España. mgmnavarro@ccee.ucm.es

\section{RESUMEN:}

Una característica que define a la sociedad de hoy en día es que nos encontramos con que el segmento de la población mayor adquiere cada día una mayor relevancia, con la consiguiente influencia que esto tiene de cara a comportamientos y hábitos de consumo. Encontramos también, que entre las diversas actividades diarias de este segmento, destinan gran parte de su tiempo a los medios de comunicación. Las personas mayores utilizan los medios de comunicación en su día a día al igual que el resto de la población y por tanto, resulta interesante profundizar, en primer lugar, conociendo a qué medios de comunicación tienen acceso, cuáles son los motivos fundamentales por los que los utilizan, el uso que les dan y los beneficios que dicha utilización les reporta, entre los cuales, encontramos aspectos relacionados con la información, el entretenimiento o la socialización. A pesar de la relevancia del tema sin embargo, son escasas las investigaciones que existen al respecto.

En el presente artículo se realiza una revisión del papel que juegan los medios de comunicación en la vida del mayor con el objetivo de constatar cuales son las funciones que dichos medios tienen en su día a día, que uso les dan y cuáles son los principales motivos que les llevan a querer establecer un contacto diario con los diferentes medios. Para ello, el estudio se enfoca desde tres perspectivas diferentes: los medios de comunicación como medio de socialización, como medio de información y por último, los medios de comunicación como medio de entretenimiento.

PALABRAS CLAVE: personas mayores - medios de comunicación - socialización ocio - entretenimiento. 


\title{
FUNCTIONS OF THE MEDIA IN THE LIFE OF AN ELDERLY
}

\begin{abstract}
A defining feature of society today is that we find the segment of the population becomes more relevant every day, resulting of behaviors and habits. We also found that among the various daily activities of this segment, people spend much of their time to the media. Older people use media in their daily lives just like the rest of the population and therefore, it is interesting to investigate, first, knowing which media access, what are the fundamental reasons why they use it, how they use them and the benefits that such use gives them among which we find aspects of information, entertainment or socialization. Despite the importance of this issue however, there is little research that exists about it.
\end{abstract}

This article reviews the role of media in the lives of the elderly in order to ascertain what are the functions of media that they use day to day, what the functions used give them and what are the main reasons that lead them to want to set a daily contact with the media. The study is approached from three different perspectives: the media as a means of socialization, as a means of information and finally, the media as a means of entertainment.

KEY WORDS: elderly - media - socialization - leisure - entertainment.

\section{Introducción}

Un hecho cierto en la sociedad española es que ésta está sufriendo un cambio importante en el incremento de personas de edad avanzada, por un lado, nos encontramos con la prolongación de la vida y por otro con el descenso en la natalidad, dando lugar de esta manera, a una proporción cada vez mayor de nuestra población (Moragas, 1991). De ahí el interés por analizar y estudiar diferentes aspectos relacionados con este segmento, porque además nos encontramos con que la edad no supone un impedimento para el desarrollo de actividades de diversa índole ni para el consumo de productos, servicios o medios de comunicación como se analiza en el presente artículo.

\section{Revisión teórica: Los efectos de los medios de comunicación}

Las personas mayores superan los 8,4 millones. En España hay 8.438.497 personas de 65 y más años, lo que supone un $18 \%$ de toda la población (INE, 2014).

Los datos a largo plazo indican que la audiencia de la televisión está envejeciendo con cierta velocidad y con una tendencia consistente, según se recoge en el Anuario de la SGAE, de las Artes Escénicas, Musicales y Audiovisuales. 
Antes de abordar en profundidad el estudio del papel que juegan los medios de comunicación en la vida de una persona mayor, se ha realizado una primera revisión de estudios y teorías existente acerca de los efectos de los medios de comunicación sobre la audiencia en general.

Entre los años veinte y ochenta del siglo XX se formularon numerosas teorías para explicar la influencia de los medios de comunicación en la sociedad, son las llamadas teorías de los efectos de los media. Encontramos que la preocupación por el análisis y la selección de los medios es situada por Romiszowski (1974) en los comienzos de la década de los setenta, concretándose en diversas propuestas clasificatorias y en la formulación de diferentes modelos, generales y particulares, de análisis de medios. Los criterios utilizados al respecto son diversos, y van desde el órgano sensorial que estimula un determinado medio, a las posibles funciones didácticas que puede desempeñar o cubrir. Son los postulados de la Teoría de los usos y gratificaciones, no obstante, investigaciones más recientes enmarcadas en esta teoría han aceptado que, incluso cuando los miembros de la audiencia son activos, los efectos pueden ocurrir y ocurren (West y Turner, 2005).

Cualquiera que sea la actitud de la audiencia ante los medios de comunicación, éstos provocan una serie de efectos en sus receptores. Existen numerosos estudios que se han centrado en estudiar cuales son los efectos de los medios de comunicación de masas. Cabe destacar las aportaciones de McQuail (1994) que introduce distinciones entre efectos planificados o deseados y no planificados o no deseados, y entre efectos que se manifiestan a corto plazo o a largo plazo. Potter (1998) complementa la clasificación de McQuail apuntando que los efectos pueden operar a distintos niveles como lo son el individual, grupal, organizacional, institucional, social y cultural. Neumann y Guggenheim (2009) establecen una división en seis módulos que contiene los modelos de persuasión, modelos de audiencia activa, modelos de contexto social, modelos de relación entre sociedad y medios, modelos de efectos interpretativos y modelos de interacción.

Por otro lado, encontramos que son varios los estudios que a lo largo de los años se han centrado en analizar de manera particular la influencia del medio televisión en las personas en diferentes niveles. Una de las influencias estudiadas alude al hecho de que el mundo televisivo suple las insuficiencias en la construcción de la realidad, sobre todo, cuando no se tienen experiencias de primera mano (Noble, 1975), o que forja los estereotipos raciales (Hartmann y Husband, 1974) o por otro lado que configura la opinión (MC Combs y Shaw, 1972).

Los medios de comunicación de masas engloban efectos que pueden clasificarse en tres niveles. Por un lado, encontramos los efectos conductuales, donde se observa que el hecho de estar expuesto a los medios de comunicación hace variar la conducta del receptor. La Agenda Setting desarrollada por McCombs y Shaw (1972) tiene como principal enfoque el estudiar la manera en la cual las noticias, el orden y la cobertura que se da a cada noticia en los diferentes medios informativos influye en la opinión pública. Según esta teoría, las personas tienden a incluir o a excluir de sus propios conocimientos lo que los medios incluyen o excluyen de su propio contenido. El público además tiende a asignar a los diferentes asuntos la misma importancia que le dan los medios en su tratamiento a personas, acontecimientos o problemas. 
Por otro lado pueden observarse efectos de los medios de comunicación también sobre las actitudes de los receptores, las cuales pueden cambiar o verse reforzadas tras la exposición a determinados medios de comunicación. Y no solamente la actitud o la predisposición puede cambiar ante la exposición a un determinado medio sino que además éstos influyen en los modos de vida: "Los personajes de televisión, si sirven para algo, es para influir en los modos de vida reales de la gente" (Valbuena, 1997).

$Y$ una tercera influencia de los medios la encontramos a nivel cognitivo. La forma de pensar y la percepción de determinadas realidades de los sujetos varían después de una continua exposición a los medios de comunicación. Los medios pueden estimular el desarrollo de diferentes procesamientos cognitivos. Saperas (1987) diferencia entre tres tipos de efectos cognitivos: los resultantes de la comunicación de masas, los resultantes de la distribución social del conocimiento y los referidos a los mensajes como constructores de realidad.

Estos tres niveles no son los únicos, pero sí quizás, los que han sido considerados con mayor relevancia en las diferentes investigaciones que se han llevado a cabo sobre el tema. Además de estos tres niveles, existen entre otros: el afectivo, el emocional y el fisiológico.

\section{El papel de las personas mayores en los medios de comunicación}

Antes de analizar el papel que juegan los medios de comunicación en la vida de una persona mayor es interesante tener en cuenta que las personas mayores no son sólo espectadores sino que también aparecen en ellos. En numerosas ocasiones el hecho de que aparezcan en los medios es el detonante para que los medios de comunicación despierten interés en ellos.

A lo largo de estos últimos 30 años, se han llevado a cabo varios estudios sobre el papel que juegan los mayores en los medios de comunicación.

El primer estudio empírico que se realizó sobre la imagen de las personas mayores en los medios lo llevó a cabo Petersen (1973) y de su estudio se pudo concluir que los mayores estaban infravalorados y apenas estaban representados en la televisión, que fue el medio que escogió para llevar a cabo su investigación.

Levinson (1973) realizó un estudio sobre series de dibujos animados en cuatro canales de televisión de Atlanta y pudo comprobar que únicamente el $4 \%$ de los roles mostrados en ellos correspondían a los roles propios de las personas mayores. Por otro lado, Arnoff (1974) examinó durante un periodo de tres años un canal de televisión y entre sus conclusiones destaca que sólo el $5 \%$ de los personajes eran personas mayores y en una proporción tres a uno eran hombres mayores. Northcott (1975) analizó 35 horas de series dramáticas durante el mes de Febrero. En los 41 shows escogidos como muestra, encontró que de los 464 roles representados por los personajes que aparecían en ellos, únicamente un 1,5\% eran roles correspondientes a personas mayores. $\mathrm{Y}$ verificó, al igual que Arnoff, que la proporción de hombres mayores frente a las mujeres mayores era de tres a uno. 
Tres años más tarde, Harris y Feinberg (1977) realizaron un estudio sobre el papel que tienen las personas mayores en los diferentes programas de televisión durante tres meses. Se escogieron programas tanto de diario como de fin de semana. De este análisis obtuvieron que únicamente en el $6 \%$ de los casos de las series televisivas los personajes eran personas mayores, en el caso de los concursos este porcentaje era del $7 \%$, mientras que en las noticias este porcentaje se elevaba al $10 \%$ y en las comedias a un $9,5 \%$. Además, generalmente las personas mayores que aparecen estaban casados.

Gerbner et al, (1980), examinaron una muestra de 1.365 programas televisivos entre los años 1969 y 1978. De toda esta gran muestra se codificaron 16.688 personajes. De esta cantidad únicamente el 2,3\% estaban representados por personas mayores de 65 años. Comprobaron además que los hombres mayores generalmente representan papeles menos serios en las comedias que los jóvenes. Por otra parte, Cassata (1980) analizó 10 episodios de series televisivas durante dos meses. Se identificaron 365 personajes diferentes y cerca del $16 \%$ de estos personajes eran personas mayores de 55 años.

Durante los años 1975 y 1979, Signorielli analizó 447 programas, en ellos se encontraron 1.298 personajes diferentes. Comprobó que un porcentaje muy pequeño de estos personajes estaba puesto en escena por personas mayores. Un $40 \%$ de las personas mayores que aparecían en estos programas estaban separados, viudos, solteros...

Del estudio realizado por Swayne y Greco (1987), también se extraen conclusiones interesantes. Analizaron 814 spots de televisión para estudiar el papel que juegan las personas mayores en los anuncios, qué tipo de productos anuncian, como están caracterizados, la posición que toman frente al resto de mayores.., entre otros temas. A partir de este análisis pudieron obtener algunas conclusiones que a continuación se detallan:

1. De los 814 spots analizados únicamente aparecían personas mayores en 50 de ellos $(6,9 \%)$ y no parecían en el $93 \%$ restante.

2. El $12 \%$ de las personas mayores que aparecen en los spots son mayores de 65 años.

3. En los spots apenas aparecen personas mayores con niños (solamente en dos spots). Suelen aparecer por lo general con otros grupos de edad, pero no con niños.

4. Los anuncios en los que aparecen mayores generalmente son los que presentan productos alimenticios, de salud y cosméticos.

5. En la mayoría de los casos las personas mayores suelen aparecer como prescriptores que transmiten información sobre el producto que están anunciando (30\% de los spots). En menos ocasiones aparecen como receptores de la información (7\%), o describiendo una situación de humor (6\%) y únicamente en un 3\% de los spots analizados aparecen desempeñando el papel de despistados y tontos.

6. En la mayoría de los spots las personas mayores no desempeñan sus roles tradicionales. 
Por su parte, Kite y Johnson (1988) llevaron a cabo una revisión de 43 estudios que se realizaron durante los años 1959 y 1984 sobre el papel que juegan las personas mayores en los medios impresos. Comprobaron que las actitudes hacia este colectivo son generalmente más negativas que las actitudes mostradas hacia los jóvenes. Sin embargo, a medida que van pasando los años, los estudios revelan que cada vez esta actitud negativa vas siendo menos significativa.

Bell (1992) analizó cinco de los programas de televisión de mayor audiencia entre las personas mayores y comprobó que la mayor parte de las personas mayores que aparecen en ellos son personas mayores activas, vitales y que apenas representan los años que realmente tienen.

También, la imagen de los mayores ha sido objeto de estudio en las revistas, Miller et al. (1999), analizaron la imagen de las personas mayores en los anuncios de las revistas durante los años 1956 y 1996 . Entre las conclusiones que obtuvieron, se pueden resaltar que a pesar que de que las personas mayores generalmente desarrollaban roles negativos, a lo largo de los años comienzan a desarrollar cada vez más roles positivos. Además las personas mayores cada vez van teniendo una mayor presencia en los anuncios de las revistas.

Igualmente reveladoras son las conclusiones del estudio realizado en el Reino Unido por Carrigan y Szmigin (1999) que analizaron la presencia de las personas mayores en los anuncios que aparecen en los medios de comunicación impresos en el Reino Unido. Algunas de las conclusiones a las que llegaron fueron: (i) que la mayor parte de los anuncios en los que se utilizaba la figura de una mayor eran de productos alimenticios, de salud y de viajes y ocio, (ii) que en Reino Unido apenas se utiliza la figura de una mayor como parte de un anuncio en un medio impreso, a no ser que el medio impreso esté dirigido expresamente hacia las personas mayores y por último (iii) que todavía ni los publicistas ni las organizaciones son conscientes de la importancia que está adquiriendo este segmento de la población como potenciales consumidores, y todavía son reacios a incluirlos en su publicidad tanto si el producto está dirigido a ellos como si está dirigido a otros segmentos.

A continuación se presenta un cuadro que resume todas las investigaciones citadas anteriormente sobre el papel que juegan las personas mayores en los medios de comunicación.

\section{Cuadro 1. Resumen estudios realizados sobre el papel que juegan las personas mayores en los medios de comunicación}

\begin{tabular}{|l|l|l|l|l|}
\hline AÑO & AUTOR & TIPO DE ESTUDIO & OBJETIVO & APORTACIONES \\
\hline 1973 & Levinson & Estudio descriptivo & $\begin{array}{l}\text { Conocer el rol que } \\
\text { desempeñan los es } \\
\text { mayores en los } \\
\text { medios }\end{array}$ & $\begin{array}{l}\text { Sólo el de la } \\
\text { muestra } \\
\text { desempeñaban } \\
\text { roles propios de } \\
\text { las personas } \\
\text { mayores }\end{array}$ \\
\hline
\end{tabular}


Elderly - media - socialization - leisure - entertainment

\begin{tabular}{|c|c|c|c|c|}
\hline 1974 & Arnoff & Estudio descriptivo & $\begin{array}{|lrr|}\text { Conocer } & \text { el } & \text { grado } \\
\text { de presencia } & \text { de los } \\
\text { mayores } & \text { en } & \text { los } \\
\text { medios } & & \text { de } \\
\text { comunicación } & \end{array}$ & $\begin{array}{l}\text { Sólo el } 5 \% \text { de la } \\
\text { muestra eran } \\
\text { mayores y en la } \\
\text { proporción } 3 \text { a } 1 \\
\text { eran hombres. }\end{array}$ \\
\hline 1974 & Northcott & Estudio descriptivo & \begin{tabular}{|lr} 
Conocer el rol & que \\
desempeñan & los \\
mayores en & los \\
medios &
\end{tabular} & 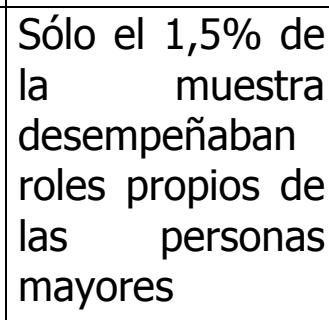 \\
\hline 1977 & \begin{tabular}{|ll} 
Harrris & $y$ \\
Feinberg &
\end{tabular} & Estudio descriptivo & 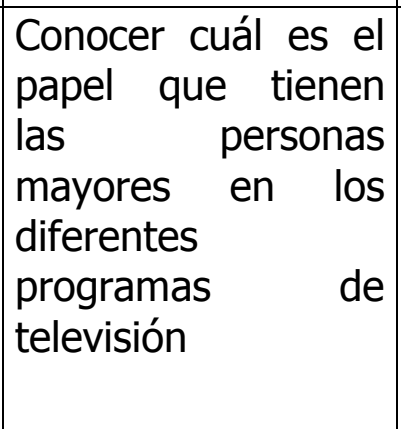 & $\begin{array}{l}\text { Son personas } \\
\text { mayores: } \quad \text { El } \\
6 \%: \quad \text { series } \\
\text { televisivas, } 7 \% \text { : } \\
\text { concursos } 10 \% \text { : } \\
\text { las comedias y } \\
\text { un } 9,5 \% \text { : } \\
\text { informativos. }\end{array}$ \\
\hline \begin{tabular}{|l|}
1969 y \\
1978
\end{tabular} & $\begin{array}{l}\text { Gerbner et } \\
\text { al. }\end{array}$ & Estudi & \begin{tabular}{|lrr} 
Conocer & el & grado \\
de presencia & de los \\
mayores & en & los \\
medios & & de \\
comunicación &
\end{tabular} & $\begin{array}{l}\text { Sólo el } 2,3 \% \text { de } \\
\text { la muestra eran } \\
\text { mayores }\end{array}$ \\
\hline 1980 & \begin{tabular}{|l|} 
Cassata, \\
Anderson y \\
Skill
\end{tabular} & Estud & $\begin{array}{|lrr|}\text { Conocer } & \text { el } & \text { grado } \\
\text { de presencia } & \text { de los } \\
\text { mayores } & \text { en } & \text { los } \\
\text { medios } & & \text { de } \\
\text { comunicación } & \end{array}$ & $\begin{array}{l}\text { Sólo el } 16 \% \text { de } \\
\text { la muestra eran } \\
\text { mayores de } 55 \\
\text { años }\end{array}$ \\
\hline $\begin{array}{l}1975 \text { y } \\
1979\end{array}$ & Signorielli & Estudio descriptivo & \begin{tabular}{|lrr} 
Conocer & el & grado \\
de presencia de los \\
mayores en & los \\
medios & de \\
comunicación &
\end{tabular} & \begin{tabular}{|lrr} 
Un & porcentaje \\
muy & pequeño \\
eran & personas \\
mayores & y & un \\
$40 \%$ & de & este \\
grupo & & eran \\
viudos, & \\
separados, & \\
solteros... &
\end{tabular} \\
\hline 1984 & Elliot & Estudio descriptivo & $\begin{array}{|lrr|}\text { Conocer } & \text { el } & \text { grado } \\
\text { de presencia de los } \\
\text { mayores } & \text { en } & \text { los } \\
\text { medios } & & \text { de }\end{array}$ & $\begin{array}{l}\text { Sólo el } 8 \% \text { de } \\
\text { la muestra eran } \\
\text { mayores de } 60\end{array}$ \\
\hline
\end{tabular}


Elderly - media - socialization - leisure - entertainment

\begin{tabular}{|c|c|c|c|c|}
\hline & & & comunicación & años \\
\hline 1986 & $\begin{array}{l}\text { Linda } \\
\text { Swayne y } \\
\text { Alan Greco }\end{array}$ & Estudio descriptivo & \begin{tabular}{|lrr} 
Conocer el & grado \\
de presencia de los \\
mayores en & los \\
medios & de \\
comunicación &
\end{tabular} & $\begin{array}{l}\text { Sólo el } 6,9 \% \text { de } \\
\text { la muestra eran } \\
\text { mayores de } 50 \\
\text { años y el } 12 \% \\
\text { eran mayores } \\
\text { de } 65 \text { años. }\end{array}$ \\
\hline 1988 & $\begin{array}{ll}\text { Kite } & y \\
\text { Johnson }\end{array}$ & Estudio descriptivo & $\begin{array}{l}\text { Analizar la imagen } \\
\text { de las personas } \\
\text { mayores en los } \\
\text { medios impresos }\end{array}$ & \begin{tabular}{|lr} 
La actitud & hacia \\
los mayores es \\
mucho & más \\
negativa & que \\
hacia & los \\
jóvenes. &
\end{tabular} \\
\hline 1992 & Bell & Estudio descriptivo & \begin{tabular}{lrrr} 
Analizar & el & rol & de \\
las & \multicolumn{2}{c}{ personas } \\
mayores & en & los \\
programas & & de \\
mayor & audiencia \\
entre las & personas \\
mayores & &
\end{tabular} & \begin{tabular}{|lr} 
Las & personas \\
mayores & que \\
aparecen & son \\
activas, & \\
vitales,.... & \\
\end{tabular} \\
\hline 1999 & $\begin{array}{l}\text { Patricia } \\
\text { Miller }\end{array}$ & Estudio descriptivo & \begin{tabular}{llll} 
Analizar & el & rol & de \\
las & \multicolumn{2}{c}{ personas } \\
mayores & en & las \\
revistas & &
\end{tabular} & $\begin{array}{lrr}\text { Cada } & \text { vez } & \text { es } \\
\text { mayor } & & \text { el } \\
\text { número } & & \text { de } \\
\text { mayores } & & \text { que } \\
\text { parecen } & \text { en } & \text { las } \\
\text { revistas } & \text { y } & \text { a } \\
\text { pesar } & & \text { de } \\
\text { desempeñar } & \\
\text { roles negativos } \\
\text { su imagen } & \text { va } \\
\text { mejorando. } & \end{array}$ \\
\hline
\end{tabular}

Fuente: Elaboración propia

Una vez revisado y analizado el papel que tienen las personas mayores en los medios de comunicación, el presente artículo se centra en el análisis de los diferentes enfoques a través de los cuales los medios de comunicación despiertan interés entre los mayores.

De los estudios sobre las funciones de los medios podemos destacar los trabajos de Berelson (1949) y Laswell (1948). El primero de ellos destacó una serie de funciones de los medios de comunicación de masas para los receptores, que pueden resumirse en los siguientes: 
- informar y ofrecer interpretaciones sobre los acontecimientos;

- constituir un instrumento esencial en la vida contemporánea;

- ser una fuente de relajación;

- atribuir prestigio social;

- ser un instrumento de contacto social;

- constituir una parte importante de los rituales de la vida cotidiana.

Por su parte, Lasswell destacó tres funciones básicas de los medios de masas en la sociedad, a las cuales Lazarsfeld y Merton (1948) añadirían una cuarta, el entretenimiento, y realizarían una serie de observaciones (en particular, el concepto de disfunción narcotizante de los medios, o fomento del conformismo social por parte de éstos). Según Lasswell, el proceso de comunicación cumple tres funciones principales en la sociedad: a) la vigilancia del entorno, revelando todo lo que podría amenazar o afectar al sistema de valores de una comunidad o de las partes que la componen; b) la puesta en relación de los componentes de la sociedad para producir una respuesta al entorno y c) la transmisión de la herencia social. Los sociólogos Lazarsfeld y Merton (1948) añaden a estas tres funciones una cuarta, el entertainment o entretenimiento, y complican el esquema distinguiendo la posibilidad de disfunciones, así como de funciones latentes y manifiestas.

A partir de estos análisis se analizan los diferentes papeles que juegan los medios de comunicación en la vida de los mayores desde tres perspectivas: como medio de socialización, de integración en la sociedad; como medio de información y como medio de entretenimiento, entre otros.

\section{Los medios de comunicación como medio de socialización (integración en la sociedad)}

En primer lugar, se analiza el papel que juegan los medios de comunicación como medio de socialización en la vida de una persona mayor. Los medios de comunicación están llamados a desempeñar el papel de primer agente socializador en las sociedades avanzadas. Estos "nuevos" agentes compiten con los agentes socializadores tradicionales como son la familia, la escuela, las amistades, etc.

Lull (1982), fue de los primeros autores que recogió la necesidad de estudiar los usos sociales de la televisión. Entre éstos se encontraban los que él denominó usos relacionales, caracterizados por resaltar el valor mediador de la pantalla en las interacciones humanas. Ésta interviene en las actividades sociales en formas muy diversas: facilitando la comunicación, logrando el grado deseado de pertenencia o exclusión a un grupo, en el aprendizaje social o en la demostración de competencia y dominio personal. Se ha demostrado que las audiencias actúan para socialmente con los personajes llegando muchas de sus estrellas a formar parte de su pensamiento.

Encontramos que los medios de comunicación son generadores y transmisores de actitudes, comportamientos, valores y opiniones. Tienen la capacidad de sensibilizar a la población acerca de determinadas realidades y de inducirles respuestas ante las 
mismas puesto que nos informan de sucesos, nos ayudan a crear opiniones o nos transmiten valores. En ocasiones su objetivo primario, informar, pasa a un segundo plano, y como objetivo prioritario encontramos la educación, una educación permanente de las personas mediante la creación de preferencias, de valores, de hábitos culturales, de mitos y anti-mitos, de costumbres (Rivière, 2003).

Asimismo, los medios de comunicación son también potentes transmisores de opiniones, ya que ejercen una gran influencia en la opinión pública y sobre la cultura de masas. En el caso de las personas mayores, ésta influencia es todavía más relevante debido a que este colectivo está en contacto con menos fuentes de información de las que poder obtener datos para crearse una opinión propia y por ello, necesitan a los medios para que les confieran una opinión. En muchos casos ésta opinión acaba siendo la opinión de la propia persona mayor sin ser contrastada con otras fuentes.

Además, se debe tener presente que los medios de comunicación transmiten ciertos modelos de comportamiento que generalmente son imitados por el receptor, marcando una serie de pautas de comportamiento social. Esto conlleva una serie de efectos positivos y otros negativos, entre éstos últimos se puede incluir el hecho de que los medios de comunicación consiguen homogeneizar a las personas reduciendo las diferencias entre las mismas creando un espectador universal; a veces los modelos de comportamiento son simplistas y conservadores y además a través de los medios se muestran comportamientos que se deben hacer y los que no se deben hacer.

El hecho de irse haciendo mayor conlleva una reducción progresiva de la comunicación cara a cara y de la interacción social (Grande, 1993) y llega un momento en que la persona mayor acaba sustituyendo la realidad misma por la que contempla en la televisión o en la radio, adquiriendo las opiniones, valores y comportamientos presentados a través de ellos.

Los medios de comunicación además de ser transmisores de valores, comportamientos y opiniones, son una fuente de apoyo social y ofrecen en sí ese apoyo social que necesitan las personas mayores al ir desapareciendo el núcleo familiar del que forman parte. El hecho de la no inserción social del mayor le provocará un fuerte sentimiento de soledad (Fernández-Ballesteros, 2012). En este colectivo, a pesar de ser amplio y diversificado, están muy presentes los sentimientos de soledad y de aislamiento social y los medios de comunicación intentan mitigar dichos sentimientos. Los medios de comunicación se convierten por tanto en un elemento de socialización y de conexión, y en el caso de la soledad son un elemento de compañía. Loyola et al., (1998) señalan que la televisión funciona como una compañía de las tareas que se realizan en el hogar, no aparece, en algunos mayores, una adhesión estricta a un programa o a un género específico sino que se consume porque acompaña al individuo en la realización de sus tareas.

Por otro lado, el hecho de leer la prensa, o escuchar la radio hace que la persona mayor reciba información que le va a permitir exponerla y confrontarla con el resto de personas con las que comparte su tiempo. Los medios de comunicación son un instrumento de identificación y de referencia social (Sanchez,2001), con lo que se consideran imprescindibles para establecer una relación entre la persona mayor y la sociedad. Los mayores van aislándose socialmente poco a poco (Bazo, 1992) y quizás 
uno de los motivos es la falta de temas de conversación. Los medios de comunicación le permiten mantenerse al día y facilitando así la labor socializadora, ya no sólo con sus amigos sino también con los miembros de su propia familia.

Al referirse a formar parte de una sociedad, no se debe olvidar que este proceso va unido a la imagen que ellos tienen de sí mismos y a la que proyectan hacia los demás. La autopercepción y la proyección de la imagen son esenciales en el proceso de envejecimiento entendido como un proceso de adaptación emocional a la pérdida marcado por las condiciones de salud y el grado de vinculación que las personas son capaces de establecer con sus contextos vitales (Prieto et al.,2009) y no cabe duda de que son estos entornos, junto con las propias variables biológicas, los que determinan e influyen en la propagación de una determinada imagen.

Como conclusión de lo comentado anteriormente se extrae que las personas mayores consiguen unos beneficios derivados de su relación con los medios de comunicación: obtener intuiciones acerca de las circunstancias de otras personas, la llamada empatía social; identificarse con otras personas; conseguir una base para mantener una conversación con el resto de personas que les rodean e interactuar con ellos; ayudar a representar roles sociales y tener la capacidad para conectar con la familia, con sus amigos y con la sociedad, además de organizar su tiempo.

\section{Los medios de comunicación como medio de información}

Una vez que ya han sido analizados los medios de comunicación desde su perspectiva como agente socializador, el presente análisis se centra en estudiar a los medios de comunicación como medios de información.

Es indiscutible la creciente influencia que juegan los medios de comunicación en la adquisición de conocimientos desempeñando una importante función educativa y formativa. Los medios de comunicación son fuentes de información a todos los niveles: económico, político, social,...., además de ser generadores de conocimiento deben facilitar la innovación, la adaptación y el progreso al mismo tiempo que proporcionan información, así como satisfacer la curiosidad y el interés general que tienen las personas. Los medios aprovechan todas sus posibilidades técnicas y aplican sus funciones comunicativas, como mediadores de informaciones y estimulaciones culturales. Además, también son considerados como canales de información, en este sentido, Gimeno y Fernández (1980) les asignan básicamente tres funciones principales: (i) por un lado, suponen un recurso para mejorar y mantener la motivación del aprendizaje, (ii) por otro tienen una importante función informativa de contenidos y por último (iii) se convierten en guías metodológicas del proceso de aprendizaje.

Las personas mayores ven en la televisión una ventana abierta al mundo, la consideran como un eslabón que une su vida con el resto de la sociedad. Los medios de comunicación ocupan un lugar importante en el desarrollo cultural de la persona 
mayor. Los medios de información aportan información sobre espacios lejanos, no conocidos en muchas ocasiones por el receptor. Los medios de comunicación eliminan factores de tiempo y de espacio creando un cambio profundo en los procesos de conocimiento. Para los medios de comunicación el espacio y el tiempo ya no son considerados obstáculos a la hora de ofrecer información.

Los medios de comunicación ejercen una gran influencia sobre las opiniones de las personas mayores, conforman sus actitudes, programan su tiempo libre y estructuran su tiempo. Así, los medios, como transmisores y generadores de opiniones, actitudes y conductas, (Kotler, 1998) han de trasladar a través de la educación estos valores a la sociedad, además de reflejar con la mayor objetividad posible lo que acontece en el mundo. Deben mostrar dicha información diariamente porque son en muchos casos la única fuente de conocimiento a la que pueden acceder millones de personas mayores.

Por tanto, los medios de comunicación constituyen una vía de divulgación de informaciones y de educación para las personas mayores (Grande, I., 1993), una muestra de ello es el creciente interés de los medios por los problemas de este colectivo, así como el creciente interés de los mayores por los programas informativos tanto a nivel general como a nivel local.

Llegados a este punto del análisis surge una pregunta, ¿̇los medios de comunicación ofrecen la información de la forma más adecuada para este colectivo?. Diversos estudios han analizado como el sistema cognitivo se deteriora con la edad, llegando incluso a observarse en un grado tal que se ha ganado un nombre propio, el de "deterioro cognitivo leve" (Torres-Quesada, ,2013). Centrándonos en el control cognitivo, cabe preguntarse si también éste se deteriora con la edad. Varios estudios indican que las personas mayores presentan déficits en tareas en las que el control cognitivo permite la resolución de conflicto entre dos respuestas (Andrés, Guerrini, Phillips y Perfect, 2008).

En numerosas ocasiones la información en los diferentes medios es excesiva para el receptor y ello hace que la persona se bloquee y se inmunice frente a la cantidad de información recibida, llegando a desinformar. Pero se debe tener en cuenta que las personas mayores presentan un déficit a la hora de organizar la información que se les transmite y dicha organización juega un papel muy importante en el procesamiento de la información, ya que una adecuada organización conlleva a un correcto almacenamiento de la información y ello contribuirá positivamente a la hora de recordar y reconocer dicha información.

Por tanto, la información se les debe presentar de forma lenta (Grande, I.,1993) y generalmente prefieren que se les facilite la información por partes separadas, además las interrupciones parece que les afectan más ellos que a los jóvenes.

Por lo que, cuando los medios de comunicación presentan una gran cantidad de información y de una forma acelerada, más que informar a los mayores les desinforma. Las personas mayores no son capaces de asimilar una gran cantidad de información y sobre todo si se trata de información nueva para ellos con la que no están familiarizados y por ello son las principales víctimas de la llamada desinformación. 
Uno de los principales motivos por los que la persona mayor debe mantenerse informado es para no desvincularse del mundo que le rodea y continuar manteniendo su vida social. El hecho de estar informados sobre la actualidad va a favorecer las relaciones con sus amigos, familiares... ya que tendrán temas de conversación comunes. Según Noelle-Neumann (1984) autora de la teoría de La Espiral del Silencio, la mayor parte de las personas tienen un miedo natural al aislamiento y a manifestar sus opiniones sin contrastarlas anteriormente. En este problema la principal fuente de información serán los medios de comunicación y serán ellos quienes definan el clima de opinión sobre los diferentes asuntos que se traten.

En definitiva, observamos que la persona mayor por el simple hecho de hacerse mayor no deja de ser consumidor de medios y como tal deberá mantenerse informado. A través de los medios, los mayores obtienen información sobre la oferta existente, sobre las novedades, precios de productos, éxitos y fracasos de cada producto, etc. Por otro lado, la publicidad es una de las formas que los medios utilizan para transmitir información y juega un papel muy importante a la hora de persuadir a las personas mayores hacia la compra de un producto. Los medios de comunicación son generadores y transmisores de actitudes, comportamientos, valores y opiniones y el proceso de compra se encuentra estrechamente vinculado a ellos.

Uno de los objetivos de los medios de comunicación desde el punto de vista formativo es el poder facilitar a las personas mayores la capacidad de tener criterio, de ser capaces de tener una opinión propia y poder seleccionar de la información que les llega aquella que no consideren relevante. Los medios de comunicación influyen sobre las personas, pero eso no significa que las manipule y que influyan de tal forma que ya no tengan opinión propia.

\section{Los medios de comunicación como medio de entretenimiento}

Para finalizar el análisis y dentro de este tercer bloque correspondiente al papel que juegan los medios en la vida de una persona mayor, se analizan los medios de comunicación desde el punto de vista del ocio como medio de entretenimiento.

Encontramos estudios que defienden que la persona necesita ser educada para utilizar su tiempo de ocio de una forma gratificante y con sentido (Weber, 1969). Enfatizando en las condiciones de libre elección y capacidad para producir placer y disfrute, diversos autores (Dumazedier, 1974; Touraine, 1973; Trilla Bernet, 1991; Cuenca, 2000 y 2004; Martínez y Gómez, 2005) coinciden en señalar que para que el ocio pueda ser considerado como tal debe cumplir las siguientes condiciones:

- Ser elegido libremente en función de preferencias individuales.

- Transmitir la sensación o sentimiento subjetivo de liberación.

- Proporcionar una sensación gratificante y placentera.

Tras el análisis realizado se observa que en general, los medios de comunicación son uno de los recursos más habituales escogidos por las personas mayores a la hora de ocupar su tiempo libre. En concreto, las personas mayores al dejar de trabajar, tienen más tiempo libre. Se debe tener en cuenta que la jubilación implica, además de la 
pérdida del rol profesional, una disminución de los ingresos económicos, una pérdida de las oportunidades de relaciones sociales derivadas del trabajo, que deberán ser sustituidas por otras, y una mayor cantidad de tiempo libre. La cantidad de tiempo libre no es constante a lo largo de toda la vida de las personas. Durante la infancia y la adolescencia resulta más amplia, mientras que se reduce al entrar en la población activa para volver a ampliarse en la jubilación.

Así, la totalidad de las horas que dedicaban a su trabajo pasan a ser horas de tiempo libre que deberán ocupar de alguna forma y una de ellas es a través de los medios de comunicación. Los mayores pasan mucho tiempo ante el televisor. Su consumo de televisión es de promedio un 3,5 por 100 superior al del total de los individuos. Las personas mayores de 65 años son los que más tiempo dedican a ver la televisión con una media de algo más de 6 horas, según CIS (2013) el 87\% de las personas mayores ven la televisión por motivos de ocio y entretenimiento.

Según el estudio realizado por Kubey (1980) el hecho de que las personas mayores dediquen tanto tiempo a ver la televisión es debido al tipo de educación que recibieron, en la que no se les preparó para otro tipo de actividades alternativas como la lectura, la música...

Por otro lado, varios estudios realizados, entre ellos el del Centro de Investigaciones sobre la Realidad Social (CIRES), se puede afirmar que las actividades de ocio más practicadas por los mayores son ver la televisión, escuchar la radio y leer los periódicos y las revistas. El orden es el mismo para el grupo de edad de 50 a 64 años que para los mayores de 65 años. Y entre las actividades menos practicadas figuran las de salir a los espectáculos (cine, teatros, ballet..), visitar galerías de arte y tocar algún instrumento musical.

Se observa por tanto que los medios de comunicación sustituyen la realidad por otro mundo, y por ello muchas personas mayores los utilizan como vía de escape, para olvidarse de sus dolores, preocupaciones o de su soledad.

Para concluir, se podría añadir que las personas mayores a través de los medios de comunicación consiguen evadirse o distraerse de los problemas; relajarse; obtener goce cultural o estético; llenar su tiempo libre y descargarse emocionalmente.

\section{Conclusiones}

La presente investigación nos ha permitido acercarnos al mundo de las personas mayores en un momento en el que se han convertido en un grupo que adquiere más importancia social cada día, tanto por su crecimiento como por las oportunidades de negocio que representa. Su conocimiento por tanto, resulta interesante ya que se desarrollan como un grupo altamente activo, participativo, como parte de un colectivo heterogéneo, que tiene gran capacidad para poder consumir, y tiempo libre que poder destinar a los medios de comunicación.

El trabajo desarrollado, pone de manifiesto algunos aspectos interesantes en la relación existente entre las personas mayores y los medios de comunicación. A lo largo del estudio se han planteado tres aspectos en la relación y el uso que los 
mayores dan a los medios de comunicación: los medios como socializadores, los medios como medios de información y por último se ha realizado el análisis de los medios como simple entretenimiento.

Por lo que respecta al primer planteamiento, los medios como socializadores, se observa como los medios de comunicación se convierten en el vehículo que va a ayudar a satisfacer algunas de sus principales necesidades: socializarse, informase y ocupar su tiempo de ocio y entretenimiento. Encontramos que se convierten en un medio de socialización puesto que son generadores y transmisores de actitudes, comportamientos, valores y opiniones, transmiten ciertos modelos de comportamiento que generalmente son imitados por el receptor, marcando una serie de pautas de comportamiento social. Y sobre todo son una fuente de apoyo social que evita la soledad y el sentimiento de asilamiento.

En relación al segundo aspecto, se apuntaba a los medios de comunicación como elementos transmisores de información. En este punto se observa como las personas mayores necesitan mantenerse informadas. Los medios aprovechan todas sus posibilidades técnicas y aplican sus funciones comunicativas, como mediadores de informaciones y estimulaciones culturales; y éstas van a ser aprovechadas por el colectivo de los mayores. Uno de los principales motivos por los que la persona mayor debe mantenerse informado es para no desvincularse del mundo que le rodea y continuar manteniendo su vida social.

Y por último, en relación al tercer aspecto analizado, los medios de comunicación como herramientas de ocio y entretenimiento, se obtiene que las personas mayores gozan de mayor cantidad de tiempo libre y los medios de comunicación son uno de los recursos más habituales escogidos por las personas mayores a la hora de ocupar su tiempo libre. Los medios de comunicación muestran mundos ficticios, que son utilizados como vía de escape, para olvidarse de preocupaciones y de su soledad, entre otros.

En definitiva, se concluye que efectivamente, los medios de comunicación juegan un papel muy relevante en la vida de las personas mayores, les ayudan a socializarse, a informarse y además les entretienen y acompañan. Estos aspectos deben tenerse en cuenta por los medios de comunicación que han de dirigirse de una forma correcta y adecuada a este segmento; igualmente resulta interesante para las empresas, conocer los usos que los mayores hacen de los medios de comunicación puesto que éstos son el vehículo que muchas compañías utilizan para llegar al segmento de mayores de manera más efectiva y eficiente. Porque los mayores de hoy en día, lejos de estar desconectados o desinteresados, son más activos y participativos que nunca.

\section{Referencias}

AGM, Informe audiencia General de Medios, 2014.

Aguaded, J. I. (1999). Educación para la «competencia televisiva». Fundamentación, diseño y evaluación de un Programa Didáctico para la formación del telespectador 
crítico y activo en Educación Secundaria (tesis doctoral inédita). Huelva. DOI: 10.3916/c31-2008-03-008.

Aguaded, J. (2000). La televisión y los escolares onubenses. Memoria de investigación. Huelva: Excmo. Ayuntamiento de Huelva y Grupo Comunicar.

Andrés, P., Guerrini, C., Phillips, L. H., \& Perfect, T. J. (2008). Differential effects of aging on executive and automatic inhibition. Developmental Neuropsychology, 33, pp.101-123. DOI: $10.1080 / 87565640701884212$

Arnoff, C. (1974). Old age in prime time. Journal of Communication, 24, pp.86-87. DOI: $10.1111 / j .1460-2466.1974 . t b 00412 . x$

Bazo, M.T. (1992). La nueva sociología de la vejez: de la teoría a los métodos. Reis, 60, pp. 75-90.

Bazo, M.T. (1992). La vejez como construcción cultural. Revista Multidisciplinar de Gerontología, 4, pp. 237-242.

Bazo, M.T. (1995). El reto del envejecimiento: una reflexión sociológica. Revista Española de Geriatría y Gerontología, 30, pp. 95-97.

Bazo, M.T. (1996). Aportaciones de las personas mayores a la sociedad: análisis sociológico. Revista Española de Investigaciones Sociológicas, 73, pp. 209-222.

Bell, J. (1992). In search of a discourse on aging: the elderly on television. The Gerontologist, 32 (3), pp. 305-311. DOI: 10.1093/geront/32.3.305

Bengston, V.; Rosenthal, C. \& Burton, L. (1996). Paradoxes of families and aging. San Diego: Academic Press.

Bengtson, V.L., \& Schaie, K.W. (Eds.). (1999). Handbook of theories of aging. New York: Springer Publishing.

Berelson, B. (1949). What "Missing the Newspaper" Means. Communication Research 1948-49. New York: Harper and Brothers.

Carrigan, M. \& Szmigin, I. (1999). The representation of older people in advertisements. Journal of the Market Research Society, 41 (3), pp. 311-326.

Cassata, D. (1980). Health communication theory and research: a definitional overview. En D. Nimmo (Ed.). Communication year book (pp.583-589). New Brunswick, NJ: Transaction.

Cassata, M.B., Anderson, P. \& Skill, T. (1992). The older adult in daytime serie drama. Journal of Communication, 30, pp. 48-49.

CIS (2013). Informe consumo de los medios de comunicación.

Connidis, I. (1989). The subjective experience of aging: Correlates of devergent views. Canadian Journal on Aging, 8, 7-18.

DOI: http://dx.doi.org/10.1017/S0714980800011168 
Cuenca, M. (2000). Ocio humanista. Dimensiones y manifestaciones actuales del ocio. Bilbao: Instituto de Estudios de Ocio, Universidad de Deusto.

Cuenca, M. (2004). Pedagogía del ocio: Modelos y Propuestas. Bilbao: Universidad de Deusto.

Dumazedier, J. (1974). Sociologie empirique du loisir. Critique et contracritiquede la civilisation du loisir. Paris: E. du Seuil.

Elliott, J. (1984). The daytime television drama portrayal of older adults. The Gerontologist, 24, pp. 628-633.

Fernández-Ballesteros, R. (1992). Mitos y realidades sobre la vejez y la salud. Barcelona: SG Editores.

García, J. (2003). Bioética y personas mayores. Informes Portal Mayores, 4. Disponible en

http://www.espaciomayores.es/InterPresent1/groups/imserso/documents/binario/garci a-bioetica-01.pdf

Grande Esteban, I. (1993). Marketing estratégico para la tercera edad. Madrid: ESIC.

Gerbner, G., Gross, N. \& Signorielli, N. (1980). Aging with television: images on television drama and conceptions of social reality. Journal of Communication, 30, pp. 37-47. DOI: $10.1111 /$ j.1460-2466.1980.tb01766.x

Gimeno, J. y Fernández, M. (1980). La formación del profesorado de EGB. Madrid: MEC.

Harris, A. \& Feinberg, J. (1977). Television and aging: is what you see what you get?. The Gerontologist, 17, pp. 464-468. DOI: 10.1093/geront/17.5_Part_1.464.

Hartmann, P. y Husband, C. (1974). Racism and the mass media. London: DavisPoynter.

Huston, A., Donnerstein, E., Fairchild, H., Feshbach, N. D., Katz, P. A.\& Murray, J. P. (1992). Big world, small screen: The role of television in American society. London: University of Nebraska Press.

INE (2014). Datos de población y censo demográfico.

IMSERSO (2011). Libro Blanco del envejecimiento activo. Dsiponible en http://www.imserso.es/InterPresent1/groups/imserso/documents/binario/8088_8089li broblancoenv.pdf

Keller, M.L., Leventhal, E.A. \& Lar-Son, B. (1989). Aging: the lived experience. International Journal of Aging and Human Development, 29, pp. 67-82. 
Kite, M. \& Johnson, B. (1988). Attitudes toward older and younger adults: a metaanalysis. Psychology \& Aging, 3, pp. 233-244. DOI: 10.1037/0882-7974.3.3.233

Kotler, P. (2013). Fundamentos de Marketing (110 ed). Madrid: Ed. Pearson.

Kubey, R. W. (1980). Television and aging: Past, present, and future. Gerontologist, 20 (1), pp. 16-35. DOI: 10.1093/geront/20.1.16

Lazarsfeld, P. y Merton. R. (1948). Comunicación de masas, gusto popular y acción social organizada. Buenos Aires: Centro Editor de América Latina.

Lehr, U. (1980). Psicología de la senectud. Barcelona: Herder.

Levinson, R. (1973). From Olive Oyle to Sweet Poly Purebread: Sex role stereotypes and televised cartoons. Journal of Popular Culture, 9, pp. 561-572.

Loyola, M., Morales, S. y Vidal, E. (1998). Los consumos de medios de comunicación en los mayores de 50 años: entre el asombro y la nostalgia. Revista Latina de Comunicación Social 11 . Disponible en www.ull.es/publicaciones/latina/a/11loyolaco.htm.

Lull, J. (1982). A rules approach to the study of television and society. Human Communication Research, 9 (1), pp. 3-16. DOI: 10.1177/009365084011003001.

Llull, J. (2001). Teoría y práctica de la educación en el tiempo libre. Madrid: Ed. CCS.

McCombs, M. \& Shaw, D. (1972). The agenda-setting function of mass media. Public Opinion Quarterly, 36, pp. 176-187.

McQuail, D. (2000). Introducción a la teoría de la comunicación de masas (3a. ed.). Barcelona: Paidós.

Martínez, S. y Góme, I. (2005). El ocio y la intervención con personas mayores. Madrid: Pearson Educación.

Miller, C. (1993). Image of seniors improves in ads. Marketing News, 6, pp. 8-11

Miller, P., Miller, D., McKibbon, E., \& Pettys, G. (1999). Stereotypes of the elderly in magazine advertisements 1956-1996. International Journal of Aging and Human Development, 49 (4), pp. 319-337. doi:10.2190/N1R6-7Q5Y-2N7Q-8NM1

Moragas, R. (1991). Gerontología social. Envejecimiento y calidad de vida. Barcelona: Herder.

Neuman, R. \& Guggenheim, L. (2009, May 21). The evolution of media effects theory: fifty years of cumulative research. Paper presented at the annual meeting of the International Communication Association, Chicago. 
Noble, G. (1975). Children in front of the small screen. London: Sage.

Noelle-Neumann, E. (1984). La opinión Pública: Nuestra piel social. Barcelona: Paidós.

Northcott, H. (1975). Too young, too old -age in the world of television. The Gerontologist, 15, pp. 184- 186.

Orozco, G. (1994). Recepción televisiva y mediaciones. La construcción de estrategias por la audiencia. En G. Orozco (Coord.). Televidencia: Perspectivas para el análisis de los procesos de recepción televisiva. Cuadernos de Comunicación y Prácticas Sociales, 6 (pp. 69-88). México: PROIICOM/Universidad Iberoamericana.

Orozco, G. (1996). Televisión y audiencias. Un enfoque cualitativo. Madrid: La Torre.

Petersen, M. (1973). The visibility and image of old people on television. Journalism Quarterly, 50, pp. 569-573.

Potter, W.J. (1998). Media Literacy. Thousand Oaks, CA; Sage.

Prieto, D., Etxeberría, I., Arritxabal, N., Galdona E., Urdaneta, J. y Yanguas L. (2009). Las dimensiones subjetivas del envejecimiento. Madrid: Imserso.

Quero, M. (2004). Televisión: niñera y compañera. Panorama actual del consumo televisivo en España. Revista de tecnología de información y comunicación educativas. Reportaje 2. Disponible en http://reddigital.cnice.mecd.es/4/reportaje2.html.

Rivière, M. (2003). El malentendido. Cómo nos educan los medios de comunicación. Barcelona: Icaria.

Romiszowski, A.J. (1974). The selection and use of instructional media. Londres: Kogan Page.

Rowe, J.W. \& Kahn, R.L. (1997). Succesful Aging. The Gerontologist, 37, pp. 433440. doi: $10.1093 /$ geront/37.4.433.

Rubinstein, E. A. (1983). Television and behavior: research conclusions of the 1982 NIMH report and their policy implications. American Psychologist, 38(7), pp. 820-825.

Sánchez, C. (2005). Estereotipos sociales. Las imágenes de la vejez en los niños y adolescentes. Málaga: Servicio de Publicaciones e Intercambio Científico de la Universidad de Málaga.

Sánchez, J.L. (1997). Crítica de la seducción mediática. Comunicación y cultura de masas en la opulencia informativa. Madrid: Tecnos. SGAE.

Sánchez, P. (2001). Consumo y efectos de los medios de comunicación en los mayores. Revista Castellano-Manchega de Ciencias Sociales, 4, pp. 159-184. 
Sánchez, P. (2001). Construcción social de los hábitos de consumo en las personas mayores. Cuadernos de Realidades Sociales, 57 - 58, pp. 95-123.

Sánchez, P. \& Bódalo, E. (1999). La imagen del mayor en los spots publicitarios de televisión. Revista Multidisciplinar de Gerontología, 9, pp. 233-242.

Sánchez, P. \& Bódalo, E. (1999). Los mayores en publicidad televisiva. Un análisis de contenido. Cuadernos de Realidades Sociales, 53-54, pp. 177-203.

Sánchez, P. \& Bódalo, E. (2000). Presencia y ausencia de los mayores en la publicidad televisiva. Revista del Ministerio de Trabajo y Asuntos Sociales, 25, pp. 19-47.

Saperas, E. (1987). Los efectos cognitivos de los medios de comunicación de masas. Barcelona: Ariel.

Snyder, M. \& Miene, P. (1994). Stereotyping of the elderly: a functional approach. British Journal of Social Psychology, 33 (1), pp. 63-82. DOI: 10.1111/j.20448309.1994.tb01011.x

Swayne, L. \& Greco, A. (1987). The portrayal of older Americans in television commercials. Journal of Advertising, 16 (1), pp. 47-54. DOI: 10.1080/00913367.1987.10673060.

Torres, M. (2006). Actitudes y motivaciones de las personas mayores hacia su desarrollo personal. Madrid: Secretaría General Técnica Consejería de Servicios Sociales.

Torres-Quesada, M. (2013). Envejecimiento y control cognitivo: ¿Dejamos de "controlar" cuando nos hacemos mayores?. Ciencia Cognitiva, 7 (3), pp. 40-42.

Touraine, A. (1973). La sociedad post-industrial. Barcelona: Ariel.

Trilla Bernet, J. (1991). Revisión de los conceptos de tiempo libre y ocio. El caso infantil. Infancia y sociedad, 8, pp. 17-32.

Valbuena, F. (1997). Teoría general de la información. Disponible en http://www.fgbueno.es/edi/val/fvtgi30.pdf.

Vera, A.L. (2005). Televisión y telespectadores. Comunicar, 25. Disponible en http://www.revistacomunicar.com/pdf/comunicar25.pdf.

Weber, E. (1969). El problema del tiempo libre. Estudio antropológico y pedagógico. Madrid: Editorial Nacional.

West, R. y Turner Lynn H. (2005). Análisis del cultivo. Teoría de la comunicación. Madrid: McGraw Hill. 